\title{
DENSIDADE DE PLANTAS E ADUBAÇÃO NITROGENADA EM COBERTURA NO DESENVOLVIMENTO E DESEMPENHO PRODUTIVO DO MILHO
}

\author{
CLAUDEMIR ZUCARELI ${ }^{1}$, DENIS PIAZZOLI ${ }^{2}$, MORYB JORGE LIMA DA COSTA SAPUCAY ${ }^{1}$, \\ ANDRÉ MATEUS PRANDO ${ }^{3}$ e JOÃO ALBERTO DE OLIVEIRA JÚNIOR ${ }^{4}$
}

\author{
${ }^{1}$ Universidade Estadual de Londrina, Londrina, PR, Brasil - claudemircca@uel.br, moryb_sapucay@hotmail.com \\ ${ }^{2}$ Monsanto do Brasil - denis.piazzoli@bayer.com \\ ${ }^{3}$ Embrapa Soja, Distrito de Warta, Paraná,Brasil - andre.prando@embrapa.br \\ ${ }^{4}$ Agricultura Inteligente (Ag.In) - joao.oliveira@agin.agr.br
}

Revista Brasileira de Milho e Sorgo, v.18, n.2, p. 178-191, 2019

\begin{abstract}
RESUMO - Alterações no arranjo de plantas na cultura do milho permitem maiores populações e exigem adequações nas doses de nitrogênio fornecidas. Objetivou-se avaliar o efeito de doses de nitrogênio em cobertura no desenvolvimento e desempenho produtivo do milho de segunda safra em diferentes densidades de plantas. O experimento foi conduzido em duas safras com o híbrido AG9010 YG, em blocos casualizados e parcelas subdivididas, com quatro repetições. Nas parcelas, alocaram-se as populações de plantas (40,60, 80 e 100 mil plantas ha-1) em espaçamento de $0,45 \mathrm{~m}$ entre linhas e, nas subparcelas, as doses de nitrogênio (ureia 45\%) em cobertura $\left(0,50,100,150 \mathrm{~kg} \mathrm{ha}^{-1}\right)$. Foram avaliados o diâmetro de colmo, a altura de inserção de espiga e de plantas, a massa da folha seca, o teor de nitrogênio na folha e nos grãos e a produtividade de grãos. A produtividade de grãos é influenciada pela interação entre população de plantas e doses de $\mathrm{N}$ em cobertura. A população de 80.000 plantas ha ${ }^{-1}$ aliada à aplicação de $120 \mathrm{~kg} \mathrm{ha}^{-1}$ de nitrogênio cobertura proporciona maior rendimento.
\end{abstract}

Palavras-chave: Zea mays, produtividade de grãos, arranjo de plantas, nitrogênio, safrinha.

\section{PLANT DENSITY AND TOPDRESSING NITROGEN FERTILIZATION ON DEVELOPMENT AND PRODUCTIVE PERFORMANCE OF MAIZE}

\begin{abstract}
Changes in the plant arrangement of corn crop allow larger populations and require adjustments in the nitrogen doses provided to maize. The objective of this study was to evaluate the effect of doses of nitrogen fertilization on the development and yield performance of second crop corn at different plant densities. The experiment was conducted in two consecutive harvests using the AG9010 YG hybrid, in randomized blocks and subdivided plots scheme, with four replications. In the main plots the plant populations (40, 60, 80 and 100 thousand plants ha $\left.\mathrm{a}^{-1}\right)$ were $^{-1}$ allocated at a spacing of $0.45 \mathrm{~m}$ between rows and the subplots were the nitrogen doses topdressing $(0,50,100,150$ $\left.\mathrm{kg} \mathrm{ha}^{-1}\right)$. Stalk diameter, ear insertion height, plant height, leaf dry mass, leaf and grain nitrogen content and grain yield were evaluated. Grain productivity was affected by the interaction between plant population and nitrogen doses topdressing. The population of $80,000 \mathrm{ha}^{-1}$ plants allied with the application of $120 \mathrm{~kg} \mathrm{ha}^{-1}$ of nitrogen topdressing, at $0.45 \mathrm{~m}$ row-spacing provided higher yield.
\end{abstract}

Keywords: Zea mays, grain yield, plant arrangement, nitrogen, off-season. 
O milho de segunda safra no Sul do Brasil é semeado em sequeiro entre os meses de janeiro e abril após a cultura de verão. Nessa modalidade de cultivo, a semeadura ocorre geralmente após a colheita da soja precoce. Durante a segunda safra, os elementos climatológicos como radiação solar, temperatura e precipitações tornam-se menos favoráveis à cultura do milho comparados aos da primeira safra (Maldaner et al., 2014), exigindo rígido acerto da época de semeadura. Além disso, é fundamental adequar práticas de manejo às condições ambientais visando obtenção de elevadas produtividades de grãos (Serpa et al., 2012). Dentre essas práticas destacam-se a escolha de híbridos adaptados, o manejo da adubação e a população de plantas (Pereira et al., 2009).

Os híbridos modernos apresentam maior rendimento e são mais resistentes a condições desfavoráveis, como deficiência hídrica e competição entre plantas, pois são mais adaptados a maiores densidades populacionais (Serpa et al., 2012). Esses híbridos possuem características importantes para o adensamento, como menor estatura de planta e altura de inserção de espiga, menor esterilidade de plantas, menor duração do subperíodo pendoamento-espigamento, angulação mais ereta das folhas, e elevado potencial produtivo (Modolo et al., 2010).

$\mathrm{O}$ incremento na densidade de semeadura aumenta a quantidade de plantas por área e, consequentemente, a competição. Ao associar este incremento à redução no espaçamento entre linhas, tem-se a maximização do uso da água, da radiação solar e dos nutrientes pelas plantas em uma determinada área, o que pode promover maiores produtividades em razão da distribuição mais equidistante das plantas e menor competição inter e intraespecífica pelos fatores de produção (Kappes et al., 2011). Em levantamento realizado por Cruz et al. (2010), com dados de 1.138 lavouras que obtiveram produtividade acima de 5.000 $\mathrm{kg} \mathrm{ha}^{-1}$ nos estados da região Centro-Oeste, em São Paulo e no Paraná, constatou-se que a média de populações de plantas de milho de segunda safra, nos diferentes espaçamentos utilizados, ficou em torno de 55 mil plantas ha-1.

O manejo nutricional é outro fator importante para que o milho expresse o máximo do seu potencial produtivo. O nitrogênio é o nutriente exigido em maior quantidade pela cultura, sendo que as recomendações da adubação em cobertura em sistema de sequeiro variam de 10 a $170 \mathrm{~kg} \mathrm{ha}^{-1}$ de $\mathrm{N}$, conforme a cultura anterior e a produtividade esperada na segunda safra (Moreira et al., 2017).

Trabalhos com genótipos, densidades de planta e níveis de nitrogênio indicam incremento na produtividade de milho à medida que se eleva a densidade de plantas, associada à maiores doses de nitrogênio (Lana et al., 2009; Melo et al., 2011). Entretanto, as respostas são divergentes uma vez que a densidade populacional ótima é determinada por diversos fatores relacionados a genótipo, ambiente e manejo da cultura (Sangoi, 2010b).

Nesse contexto, considerando que o aumento na densidade de semeadura eleva a competição entre plantas, principalmente em condições climáticas específicas de segunda safra, é necessária adequação da aplicação de nitrogênio em cobertura para suprir as exigências do milho submetido a maiores adensamentos populacionais. Portanto, objetivou-se avaliar o efeito de doses da adubação nitrogenada em cobertura em diferentes densidades de plantas no desenvolvimento e desempenho produtivo do milho de segunda safra. 


\section{Material e Métodos}

O experimento foi conduzido na Fazenda Monteiro (altitude $430 \mathrm{~m}$ ), localizada no Distrito Rural da Prata, Cambé-PR (2316’'S e $\left.51^{\circ} 17^{\prime} \mathrm{O}\right)$, em duas safras consecutivas (2009 e 2010), em um Latossolo Vermelho distroférrico (LVdf). De acordo com a classificação de Köppen, o clima característico da região é do tipo Cfa, subtropical úmido mesotérmico, com verões quentes e geadas pouco frequentes. As chuvas tendem a se concentrar nos meses de verão, sem estação seca definida, com precipitação pluvial média anual de $1.614 \mathrm{~mm}$ e insolação média anual de 7,05 horas por dia. A temperatura média anual é de 20,2 ${ }^{\circ} \mathrm{C}$, a média das temperaturas máximas é de $27,0{ }^{\circ} \mathrm{C}$ e das temperaturas mínimas, de $14,8^{\circ} \mathrm{C}$, com umidade relativa do ar média de 75\% (IAPAR, 2018a). Os dados de precipitação pluvial e temperatura durante a condução dos experimentos foram coletados na estação do Instituto Agronômico do Paraná (IAPAR), em Bela Vista do Paraíso-PR, a 16 km da área experimental (Figura 1).

O delineamento experimental utilizado foi blocos casualizados em esquema de parcelas subdivididas, com quatro repetições. Nas parcelas, alocaram-se as populações de plantas (40, 60, 80 e 100 mil plantas ha $^{-1}$, ou 4; 6; 8 e 10 plantas $\mathrm{m}^{-2}$ ) e, nas subparcelas, as doses de nitrogênio em cobertura $(0,50,100,150$ $\mathrm{kg} \mathrm{ha}^{-1}$ ), totalizando 16 tratamentos. A parcela experimental foi composta por oito linhas com cinco metros de comprimento, espaçadas de $0,45 \mathrm{~m}$, considerandose como área útil as quatro linhas centrais, totalizando $9 \mathrm{~m}^{2}$.

Em ambas as safras, os experimentos foram instalados após a cultura de soja, precedida pela cultura do trigo no inverno. Antes da instalação, foram coletadas amostras de solo de 0-20 cm de pro- fundidade, cujos resultados foram: Ano $1-5,5 \mathrm{pH}$ $\left(\mathrm{CaCl}_{2}\right) ; 9,8 \mathrm{mg} \mathrm{dm}^{-3} \mathrm{P}\left(\right.$ Melich $\left.^{-1}\right) ; 28 \mathrm{~g} \mathrm{~kg}^{-1} \mathrm{MO} ; 0,0$ cmolc $\mathrm{dm}^{-3} \mathrm{Al} ; 5,1 \mathrm{cmolc} \mathrm{dm}^{-3} \mathrm{H}+\mathrm{Al} ; 0,44$ cmolc $\mathrm{dm}^{-3} \mathrm{~K} ; 5,3 \mathrm{cmolc} \mathrm{dm}^{-3} \mathrm{Ca}$; 1,5 cmolc $\mathrm{dm}^{-3} \mathrm{Mg} ; 7,2$ cmolc $\mathrm{dm}^{-3} \mathrm{SB} ; 13,8$ cmolc $\mathrm{dm}^{-3} \mathrm{CTC}$; e $63 \% \mathrm{~V}$; e Ano 2 - 5,2 $\mathrm{pH}\left(\mathrm{CaCl}_{2}\right) ; 13,6 \mathrm{mg} \mathrm{dm}{ }^{-3} \mathrm{P}\left(\mathrm{Melich}^{-1}\right)$; $28 \mathrm{~g} \mathrm{~kg}^{-1} \mathrm{MO}$; 0,0 cmolc dm${ }^{-3} \mathrm{Al} ; 4,7 \mathrm{cmolc} \mathrm{dm}^{-3}$ $\mathrm{H}+\mathrm{Al} ; 0,4 \mathrm{cmolc} \mathrm{dm}^{-3} \mathrm{~K} ; 7,6 \mathrm{cmolc} \mathrm{dm}^{-3} \mathrm{Ca} ; 1,7$ cmolc dm ${ }^{-3} \mathrm{Mg} ;$ 9,7 cmolc dm ${ }^{-3} \mathrm{SB} ; 14,3$ cmolc dm$^{-3}$ CTC; e $67 \% \mathrm{~V}$.

$\mathrm{Na}$ semeadura, foram aplicados $25 \mathrm{~kg}$ de $\mathrm{N}$ ha $^{-1}$ (sulfato de amônio), $35 \mathrm{~kg}$ de $\mathrm{P}_{2} \mathrm{O}_{5} \mathrm{ha}^{-1}$ como (superfosfato simples) e $35 \mathrm{~kg}$ de $\mathrm{K}_{2} \mathrm{O}$ ha $^{-1}$ (cloreto de potássio). Antes da semeadura, as sementes de milho híbrido (cv. AG9010 YG) foram tratadas com o fungicida fludioxonil $(0,0375 \mathrm{~g}$ i.a. $)+$ metalaxyl-m, $(0,015 \mathrm{~g}$ i.a. $)$ por $\mathrm{kg}^{-1}$ de semente, e com o inseticida imidacloprido (52,5 g i.a.) + tiodicarbe (157,5 g i.a.) para 60.000 sementes. Com a semeadora adubadora realizou-se a deposição do adubo e a demarcação das linhas, e com matraca efetuou-se a semeadura de duas sementes por cova. Quando as plantas apresentavam duas folhas expandidas, realizou-se o desbaste, deixando-se apenas uma planta por cova.

A adubação nitrogenada de cobertura foi realizada quando as plantas estavam entre os estádios de V3 e V4 (três a quatro folhas completamente expandidas). Na primeira safra, a fonte de nitrogênio foi a ureia $(45 \% \mathrm{~N})$ com inibidor de urease, e na segunda safra, nitrato de amônio ( $32 \% \mathrm{~N})$, aplicados em cobertura sobre a superfície do solo.

Por ocasião do florescimento foram determinados a massa da folha seca (MFS) e o teor de nitrogênio na folha (NF). Para obtenção da massa foliar seca, quando 50\% das plantas de cada tratamento atingiram florescimento, foram coletadas ao acaso quatro folhas por parcela, selecionando-se a folha oposta e abaixo 

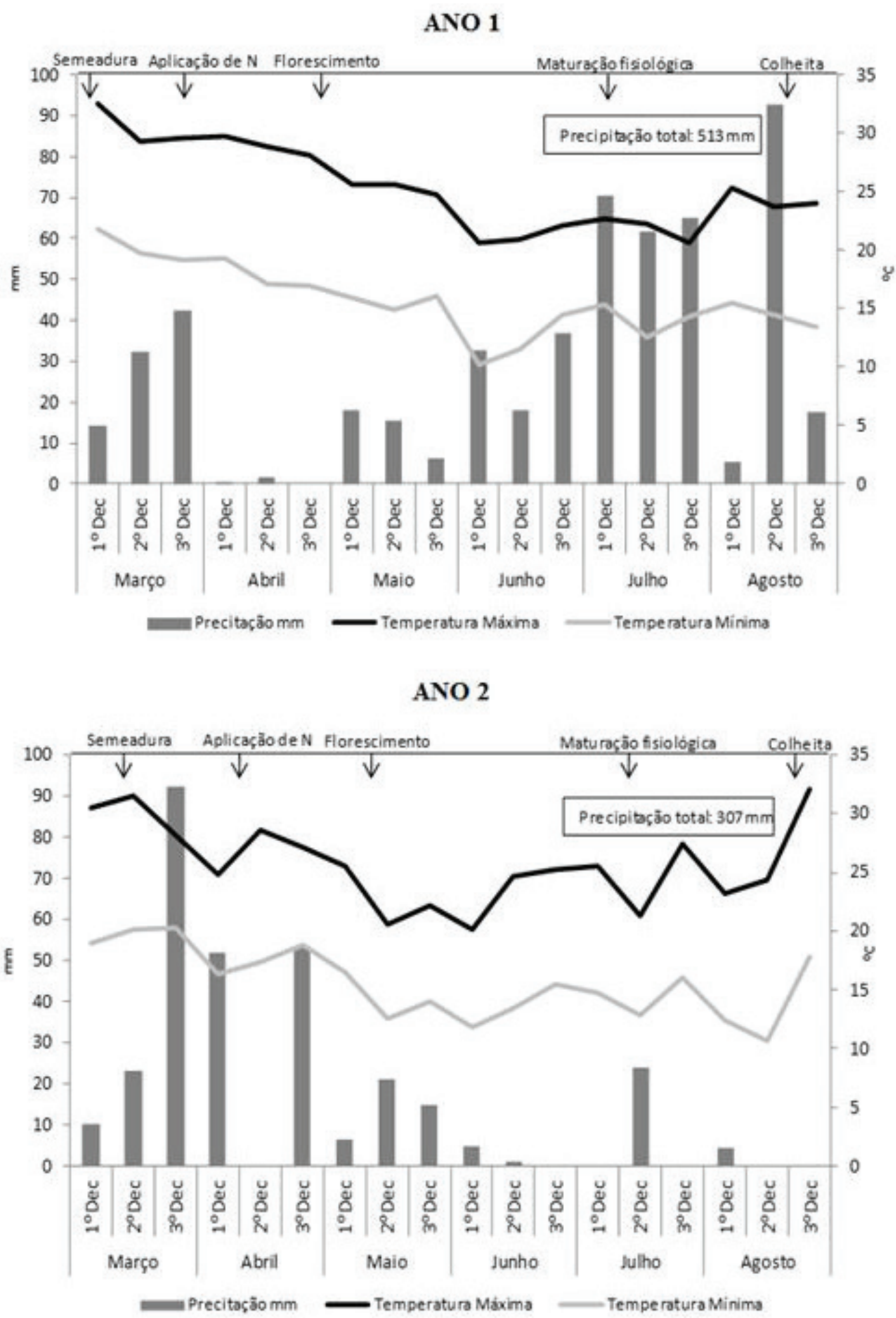

Figura 1. Precipitação pluvial, temperaturas máximas e mínimas, por decêndio, no período de 01/03 a 31/08, em duas safras consecutivas, registrados pelo Instituto Agronômico do Paraná de Bela vista do Paraíso-PR. 
da espiga. As folhas coletadas foram acondicionadas em sacos de papel e levadas para o laboratório, onde foram lavadas com água destilada, secas em estufa de ventilação forçada a $65^{\circ} \mathrm{C}$ até atingir massa constante para determinação da massa foliar seca. Em seguida, o terço central dessas folhas foi moído e homogeneizado para uso na determinação do nitrogênio foliar pelo método de Kjeldahl.

$\mathrm{Na}$ maturação de colheita (cerca de $20 \%$ de umidade) foram tomadas ao acaso seis plantas, na área útil da parcela, para avaliação das seguintes características: diâmetro de colmo (DC) (mensurado no segundo internódio a partir da base da planta, no sentido da saída das folhas dos colmos); altura de inserção de espiga (IE) (distância entre a superfície do solo e o ponto de inserção da espiga principal com o colmo); e altura da planta (AP) (medida entre a superfície do solo até a base do limbo da última folha); teor de nitrogênio nos grãos (NG); e produtividade de grãos (PROD). Após a trilha, beneficiamento e determinação da massa de grãos, os dados de produtividade de cada tratamento foram corrigidos para $13 \%$ de umidade e expressos em kg ha-1. Para o teor de $\mathrm{N}$ nos grãos utilizou-se a mesma metodologia utilizada para determinação do teor de $\mathrm{N}$ foliar.

Os dados foram submetidos às análises de normalidade e homocedasticidade, e os testes de Shapiro-Wilk e Hartley foram utilizados, respectivamente, indicando a inexistência de necessidade de transformação dos dados e o cumprimento dos pressupostos para análise de variância. Em seguida, os dados foram submetidos à análise de variância $(\mathrm{p} \leq 0,05)$ e análise de regressão até o $2^{\circ}$ grau, com análise conjunta das duas safras de condução do experimento, utilizando o programa de análise estatística Sisvar (Ferreira, 2011).

\section{Resultados e Discussão}

Nos dois anos do experimento, as precipitações foram inferiores à média histórica da região, visto que dados climatológicos de pluviosidade indicam média de $586 \mathrm{~mm}$ no período de março a agosto (IAPAR, 2018b). Embora o volume total de precipitação pluvial ocorrida no primeiro ano de condução do experimento $(513 \mathrm{~mm})$ tenha sido maior que no segundo ano (307 mm), praticamente não houve precipitações no mês de abril daquele ano, fato que coincidiu com os estádios de V5 a Vt (cinco folhas completamente expandidas e emissão do pendão, respectivamente), reduzindo o potencial produtivo do milho no primeiro ano (Figura 1). Considerando que para alcançar elevada produção a cultura do milho necessita de 400 a $600 \mathrm{~mm}$ de água durante o ciclo (Fancelli, 2015), a baixa precipitação pluvial no segundo ano foi compensada pela sua distribuição favorável ao desenvolvimento do ciclo do milho, com a concentração maior no início e meio do ciclo, ao contrário do que ocorreu no primeiro ano.

As temperaturas ótimas para o milho estão entre 25 e $30{ }^{\circ} \mathrm{C}$, com temperatura basal de $10{ }^{\circ} \mathrm{C}$ e superior de $42{ }^{\circ} \mathrm{C}$ (Sangoi et al., 2010a). Durante o experimento as temperaturas variaram de 10 a 32 ${ }^{\circ} \mathrm{C}$. No primeiro ano, houve redução brusca $\left(10{ }^{\circ} \mathrm{C}\right)$ durante a fase de enchimento dos grãos, no primeiro decêndio de junho (Figura 1). No segundo ano, a redução da temperatura mínima por ocasião do inverno ocorreu de forma mais gradual, chegando a $12{ }^{\circ} \mathrm{C}$, fato que afetou menos o crescimento e o desenvolvimento das plantas que no ano anterior.

Na Tabela 1 é apresentado o resumo da análise de variância para as características avaliadas em resposta aos efeitos isolados e interação entre os fatores estudados. Tanto em um ano quanto no outro, à me- 
dida que aumentou a população de milho por área, por meio do incremento na densidade de plantas (4 a 10 plantas $\mathrm{m}^{-2}$ ), o diâmetro do colmo foi reduzido de forma linear (Tabela 1 e Figura 2a). Essa redução também foi obtida por Kappes et al. (2011), estudando o efeito do arranjo de plantas sobre cultivares de milho. A maior competição entre as plantas fragiliza o colmo porque as plantas, na tentativa de evitar o sombreamento e captar mais luz, buscam crescimento acima do dossel quando submetidas a elevadas populações, uma vez que os fotoassimilados são direcionados para promover rápido crescimento, reduzindo outras partes como o diâmetro de colmo (Taiz \& Zeiger, 2017).
Em resposta a doses de nitrogênio em cobertura, o diâmetro do colmo ajustou-se a uma equação quadrática (Tabela 1), com ponto de máxima em 92,2 $\mathrm{kg} \mathrm{ha}^{-1}$ (Figura 2b). Esse resultado corrobora o obtido por Soratto et al. (2010), em que doses (0, 30, 60, 90 e $120 \mathrm{~kg} \mathrm{ha}^{-1}$ ) de quatro diferentes fontes de $\mathrm{N}$ em cobertura com densidade de 6 plantas $\mathrm{m}^{-2}$ permitiram alcance do ponto de máxima em $93,7 \mathrm{~kg} \mathrm{ha}^{-1}$. Notadamente a redução no diâmetro do colmo pelo aumento da população pode ser atenuada com o incremento de $\mathrm{N}$ em cobertura. A manutenção do diâmetro do colmo é importante, pois o órgão equilibra a limitação da fonte de carboidratos por meio da remobilização de reservas armazenadas até a fase enchimento dos

Tabela 1. Análise de variância da regressão para densidades de plantas e doses de nitrogênio aplicadas em cobertura no milho de segunda safra, Cambé-PR.

\begin{tabular}{|c|c|c|c|c|c|c|c|c|}
\hline Fontes de variação & GL & $\begin{array}{l}\text { DC } \\
(\mathrm{m}) \\
\end{array}$ & $\begin{array}{l}\text { IE } \\
(\mathrm{m})\end{array}$ & $\begin{array}{l}\text { AP } \\
(\mathrm{m}) \\
\end{array}$ & $\begin{array}{c}\text { MSF } \\
(\mathrm{g})\end{array}$ & $\begin{array}{c}\mathrm{NF} \\
\left(\mathrm{g} \mathrm{kg}^{-1}\right)\end{array}$ & $\begin{array}{c}\mathrm{NG} \\
\left(\mathrm{g} \mathrm{kg}^{-1}\right)\end{array}$ & $\begin{array}{l}\text { PROD } \\
\left(\mathrm{kg} \mathrm{ha}^{-1}\right)\end{array}$ \\
\hline & & & & & pValor & & & \\
\hline BLOCO (ANO) & 6 & $0,56^{\mathrm{ns}}$ & $0,16^{\mathrm{ns}}$ & $0,32^{\mathrm{ns}}$ & $0,15^{\mathrm{ns}}$ & $0,47^{\mathrm{ns}}$ & $0,04 *$ & $0,03 *$ \\
\hline POPULACÃO (P) & 3 & $0,00 * *$ & $0,00 * *$ & $0,00 * *$ & $0,00 * *$ & $0,00 * *$ & $0,04 *$ & $0,00 * *$ \\
\hline RL - linear & 1 & $0,00 * *$ & $0,00 * *$ & $0,00 * *$ & $0,00 * *$ & $0,00 * *$ & $0,03 *$ & $0,00 * *$ \\
\hline RQ - quadrática & 1 & $0,08^{\mathrm{ns}}$ & $0,27^{\mathrm{ns}}$ & $0,08^{\mathrm{ns}}$ & $0,14^{\mathrm{ns}}$ & $0,17^{\mathrm{ns}}$ & $0,09^{\mathrm{ns}}$ & $0,00 * *$ \\
\hline Erro (a) & 18 & & & & & & & \\
\hline DOSE N (D) & 3 & $0,04^{*}$ & $0,02 *$ & $0,00^{* *}$ & $0,01 * *$ & $0,00 * *$ & $0,02 *$ & $0,00^{* *}$ \\
\hline RL - linear & 1 & $0,14^{\mathrm{ns}}$ & $0,04 *$ & $0,00^{* *}$ & $0,00 * *$ & $0,00^{*}$ & $0,03 *$ & $0,00^{* *}$ \\
\hline $\mathrm{RQ}$ - quadrática & 1 & $0,04^{*}$ & $0,02 *$ & $0,01^{* *}$ & $0,44^{\mathrm{ns}}$ & $0,08^{\mathrm{ns}}$ & $0,57^{\mathrm{ns}}$ & $0,00^{* *}$ \\
\hline $\mathrm{D} * \mathrm{P}$ & 9 & $0,75^{\mathrm{ns}}$ & $0,76^{\mathrm{ns}}$ & $0,09^{\mathrm{ns}}$ & $0,41^{\mathrm{ns}}$ & $0,35^{\mathrm{ns}}$ & $0,44^{\mathrm{ns}}$ & $0,00^{* *}$ \\
\hline Erro (b) & 72 & & & & & & & \\
\hline Média Geral & & 0,01 & 0,8 & 1,7 & 2,4 & 26,2 & 12,5 & $6.541,0$ \\
\hline $\mathrm{CV}$ (a) $\%$ & & 7,5 & 6,1 & 2,69 & 11,5 & 8,5 & 7,7 & 5,5 \\
\hline $\mathrm{CV}(\mathrm{b}) \%$ & & 6,8 & 7,0 & 3,02 & 10,0 & 11,2 & 6,4 & 4,5 \\
\hline
\end{tabular}

ns: não significativo; *: significativo $(\mathrm{p} \leq 0,05) \mathrm{e}^{* *}$ : significativo $(\mathrm{p} \leq 0,01)$, respectivamente, pelo teste F. GL: graus de liberdade, DC: diâmetro de colmo; IE: inserção de espiga; AP: altura de planta; MSF: massa da folha seca; NF: teor de nitrogênio foliar; NG: teor de nitrogênio no grão; e PROD: produtividade. 

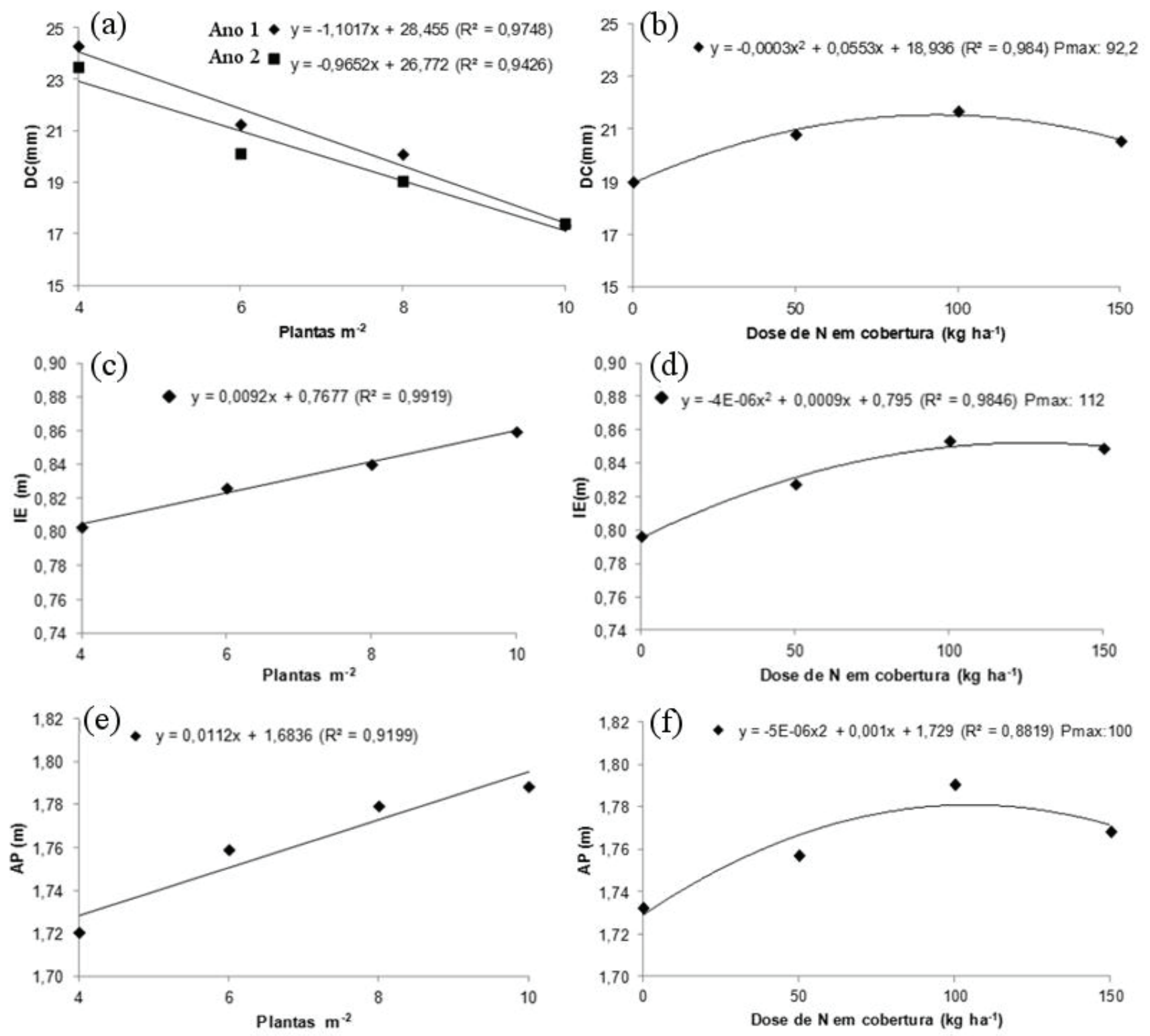

Figura 2. Diâmetro de colmo (DC) em função da interação entre densidade de plantas e ano de cultivo (a), e em função de doses de nitrogênio (N) em cobertura (b), altura de inserção da espiga (IE) e altura de planta (AP) em função da densidade de plantas (c e e, respectivamente) e em função de doses de nitrogênio (N) em cobertura ( $\mathrm{d}$ e f, respectivamente) na cultura do milho, Cambé-PR.

grãos (Sangoi et al., 2001), sendo, portanto, de grande importância a manutenção ou incremento do seu diâmetro nas condições de estresse que comumente ocorrem na segunda safra, principalmente sob alta competição intraespecífica.
O acréscimo na densidade de plantas proporcionou também aumento linear na altura de inserção de espiga (IE) $(0,80$ a $0,86 \mathrm{~m})$ e na altura de plantas (AP) $(1,73$ a 1,79 m) (Tabela 1 e Figura 2c e 2e), vale ressaltar que estes incrementos podem ser considera- 
dos de baixa magnitude. Von Pinho et al. (2008), avaliando híbridos com populações de até 85.000 plantas $\mathrm{ha}^{-1}$, encontraram o mesmo comportamento. Sob altas densidades populacionais tem-se maior dominância apical, uma vez que menos luz atinge o ponto de crescimento da planta e degrada menos auxinas, as quais estimulam a divisão e elongação celular, formando plantas mais altas e com maior altura de inserção das espigas (Kappes et al., 2011).

A inserção da espiga e a altura de planta se ajustaram a equações quadráticas em reposta as doses de nitrogênio em cobertura com pontos de máxima em 112 e $100 \mathrm{~kg} \mathrm{ha}^{-1}$, respectivamente (Tabela 1 e Figura 2d e 2f). Plantas com maior altura de inserção da espiga e altura de planta podem ser mais suscetíveis ao acamamento ou quebramento (Farinelli et al., 2012), os quais não foram observados nesse experimento, possivelmente pelas características de menor sensibilidade do híbrido AG9010 YG a esses problemas. Lana et al. (2009) também observaram resposta positiva da inserção de espiga (1,31 a 1,36 m) e altura de planta (2,4 a 2,46 m) com o aumento da dose de $\mathrm{N}$ em cobertura $\left(0,30,60\right.$ e $90 \mathrm{~kg}$ de $\left.\mathrm{N} \mathrm{ha}^{-1}\right)$ utilizando o híbrido simples Pioneer 30F33, mas com resposta linear. A resposta positiva da planta em altura e em altura de inserção da espiga à dose de nitrogênio em cobertura ocorre porque o nutriente influencia diretamente a divisão e a expansão celular, bem como o processo fotossintético, favorecendo o desenvolvimento vegetativo (Prado, 2008).

A altura de planta foi influenciada ainda pelo ano de cultivo, com maior altura no ano $2(1,78 \mathrm{~m}) \mathrm{em}$ relação ao ano $1(1,74 \mathrm{~m})$, provavelmente, por causa das distintas condições climáticas ocorridas entre os anos avaliados (Figura 1), sugerindo um aumento natural na altura das plantas em ambientes mais favoráveis ao seu crescimento, como no segundo ano, em que ocorreu melhor distribuição das chuvas no período vegetativo do ciclo.

Em função do incremento na densidade de plantas, observou-se redução linear da massa da folha seca (MSF) (Tabela 1 e Figura 3a). Em condição de maior competição interespecífica ocorrem alterações na arquitetura da planta e no desenvolvimento foliar, uma vez que para maior interceptação da radiação solar a planta prioriza maior elongação de entrenós (colmos mais longos, porém de menor diâmetro), dominância apical e altura de inserção de espiga (Almeida et al., 2000), em detrimento da área foliar, causando redução na área foliar, e, por conseguinte, na sua massa. A menor área foliar pode implicar redução da fotossíntese, resultando em menor disponibilidade de fotoassimilados para o enchimento de grãos e manutenção das demais estruturas do vegetal (Brito et al., 2011). Entretanto, a arquitetura dos híbridos modernos, caso do AG9010 YG, possibilita a utilização de uma maior quantidade de plantas por área sem causar sombreamento de plantas vizinhas e diminuir o rendimento dos grãos.

Ao contrário do que foi obtido com o aumento na densidade de plantas, a massa da folha seca apresentou resposta linear crescente ao incremento de doses de nitrogênio em cobertura (Tabela 1 e Figura 3b), evidenciando a importância do nutriente para mitigar o efeito da competição entre plantas quando se utilizam populações mais elevadas.

$\mathrm{O}$ incremento na densidade de plantas reduziu linearmente o teor de nitrogênio na folha (NF) e no grão (NG) (Figura 3c e $3 \mathrm{e}$ ), enquanto o incremento de doses de nitrogênio em cobertura proporcionou aumento linear para as mesmas variáveis (Tabela 1 e Figura 3d e 3f). Valores de nitrogênio nas folhas e nos grãos descritos como adequados para cada tonelada de grãos produzidos (27,0 a 35,0 $\mathrm{g}^{\mathrm{de} \mathrm{N} \mathrm{kg}^{-1}}$ 

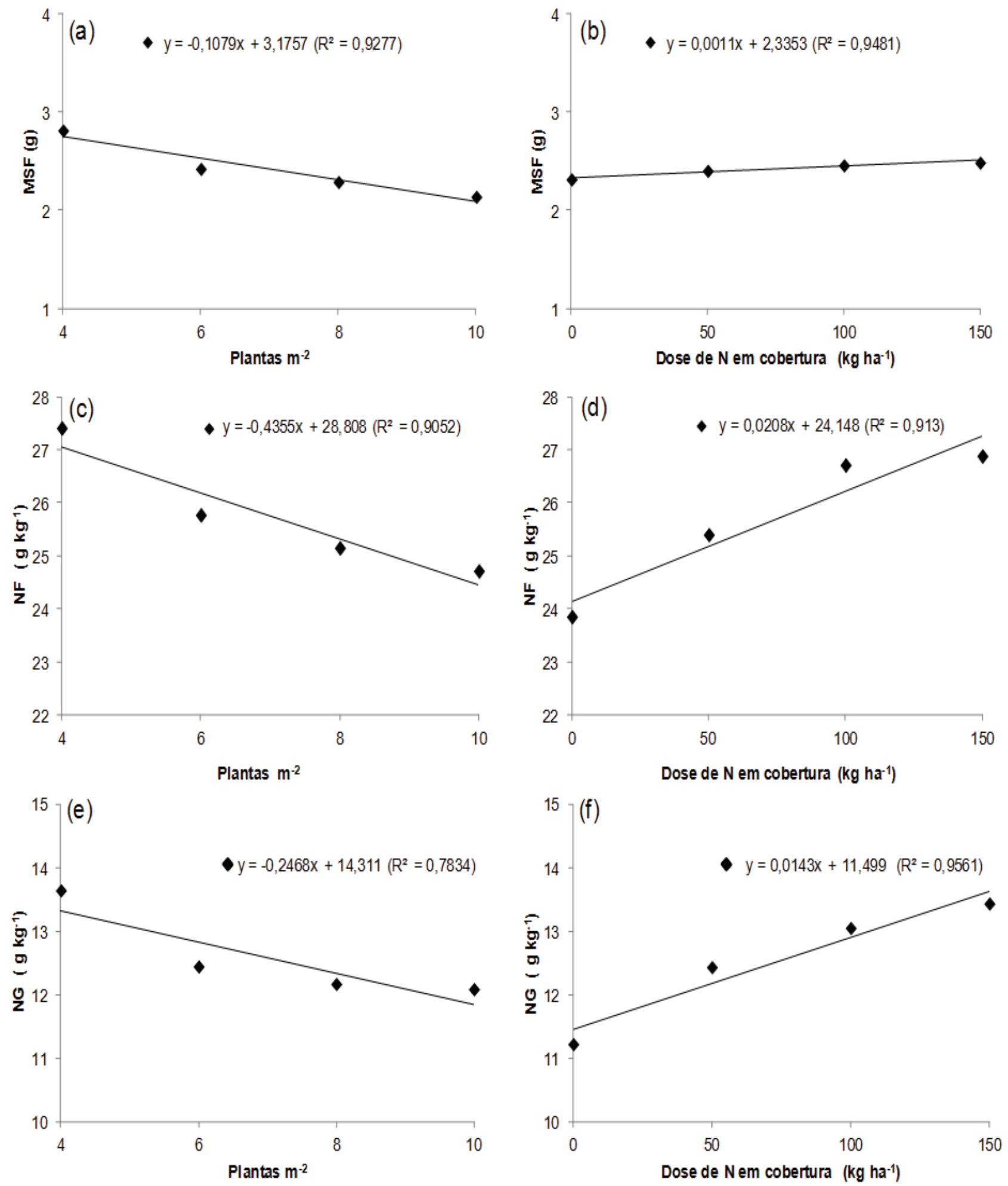

Figura 3. Massa da folhaseca(a eb), teor de nitrogênio na folha (ce d) eteor denitrogênio nos grãos (e ef), em função de densidades de plantas e em função de doses de nitrogênio $(\mathrm{N})$ em cobertura na cultura do milho, Cambé-PR. 
de matéria seca) (Moreira et al., 2017) dão uma ideia da condição nutricional da planta e indicam a dependência do rendimento em relação à disponibilidade de nitrogênio. Para teor de nitrogênio na folha, os resultados atingiram o valor mínimo adequado quando a dose de $\mathrm{N}$ em cobertura foi $137,1 \mathrm{~kg} \mathrm{ha}^{-1}$, enquanto o teor de nitrogênio no grão ficou abaixo da quantidade exportada mínima necessária $\left(14,4 \mathrm{~g}^{\mathrm{de}} \mathrm{N} \mathrm{kg}^{-1} \mathrm{de}\right.$ matéria seca) para cada tonelada produzida (Moreira et al., 2017).

Nos dois anos avaliados, a densidade de plantas influenciou a produtividade de grãos nas doses de $50,100,150 \mathrm{~kg} \mathrm{ha}^{-1}$ de $\mathrm{N}$ em cobertura, ajustando-se, em geral, à função quadrática, com ponto máximo em 8,05 e 8,09 plantas $\mathrm{m}^{-2}$, o que resultou em produtividades de $7.233 \mathrm{~kg} \mathrm{ha}^{-1}\left(1^{\mathrm{o}}\right.$ ano) e $7.799 \mathrm{~kg} \mathrm{ha}^{-1}$ ( $2^{\circ}$ ano) na dose de $100 \mathrm{~kg} \mathrm{ha}^{-1} \mathrm{de} \mathrm{N}$ (Figura 4a e 4b). No primeiro ano, mesmo quando não se aplicou nitrogênio em cobertura, houve resposta quadrática na produtividade de grãos com o incremento na população de plantas, sendo o ponto máximo obtido com 7,86 plantas $\mathrm{m}^{-2}$ (Figura 4a). Todavia, com $0 \mathrm{~kg}$ de $\mathrm{N}$ em cobertura a produtividade média foi inferior às proporcionadas pelas demais doses de N. No segundo ano, o incremento na densidade de plantas não influenciou na produtividade de grãos quando não se aplicou $\mathrm{N}$ em cobertura (Figura 4b). Utilizando espaçamento de 0,45 m, Von Pinho et al. (2008) alcançaram máximo rendimento de grãos quando utilizaram densidade de 8,5 plantas $\mathrm{m}^{-2}$ e fizeram adubação nitrogenada de cobertura com $120 \mathrm{~kg} \mathrm{ha}^{-1}$.

Nos dois anos avaliados, as doses de $\mathrm{N}$ em cobertura afetaram a produtividade de grãos nas densidades populacionais de 4, 6, 8 e 10 plantas $\mathrm{m}^{-2}$, ajustando-se, em geral, à função quadrática, com pontos máximos na aplicação de 103,39 e 120,05 kg de N $\mathrm{ha}^{-1}$ em cobertura, resultando na produtividade de
$7.200 \mathrm{~kg} \mathrm{ha}^{-1}\left(1^{\mathrm{o}}\right.$ ano $)$ e $7.771 \mathrm{~kg} \mathrm{ha}^{-1}\left(2^{\circ}\right.$ ano) na densidade de 8 plantas $\mathrm{m}^{-2}$ (Figura $4 \mathrm{c}$ e $4 \mathrm{~d}$ ). Soratto et al. (2010), com aumento da produtividade de grãos do milho segunda safra com a aplicação de $120 \mathrm{~kg}$ de $\mathrm{N}$, utilizando espaçamento de $0,8 \mathrm{~m}$ entre linhas e 8 plantas $\mathrm{m}^{-2}$.

No segundo ano, apenas para a menor densidade utilizada ( 4 plantas $\mathrm{m}^{-2}$ ) houve resposta linear crescente na produtividade de grãos com o incremento na adubação nitrogenada de cobertura, sendo o máximo obtido (6.037 $\left.\mathrm{kg} \mathrm{ha}^{-1}\right)$ quando a dose foi de 150 $\mathrm{kg}$ (Figura 4d). A menor produtividade em relação às demais densidades ocorre porque o milho tem baixa capacidade de compensação de área, pois possui limitada capacidade de expansão foliar, prolificidade e emissão de afilhos férteis (Sangoi et al., 2010b).

Na comparação entre os anos em função de densidade de plantas e doses de nitrogênio (N) aplicado em cobertura, a produtividade do segundo ano superou a do primeiro nas seguintes combinações de densidade e dose de $\mathrm{N}$ em cobertura: 8 plantas $\mathrm{m}^{-2}$ com $150 \mathrm{~kg} \mathrm{ha}^{-1}$; e 10 plantas $\mathrm{m}^{-2}$ com 50 e $150 \mathrm{~kg}$ $\mathrm{ha}^{-1}$ (Tabela 2). Nota-se que o cultivo do milho segunda safra é muito influenciado por fatores climáticos como temperatura, luz e, principalmente, precipitação pluvial (Pereira et al., 2009), de maneira que as condições ambientais nos anos proporcionaram diferenças significativas na média de produtividade dos experimentos, com variações de 717 a $918 \mathrm{~kg} \mathrm{ha}^{-1}$ de grãos.

A máxima produtividade $\left(7.771 \mathrm{~kg} \mathrm{ha}^{-1}\right)$ foi alcançada quando se utilizou no espaçamento de 0,45 m, 8 plantas $\mathrm{m}^{-2}$ e $120 \mathrm{~kg} \mathrm{ha}^{-1}$ de $\mathrm{N}$ em cobertura. Melo et al. (2011) também observaram máximo rendimento de grãos o milho com $120 \mathrm{~kg} \mathrm{ha}^{-1} \mathrm{~N}$ e densidade de 80.000 plantas ha $^{-1}$. Por outro lado, Lana et al. (2014) encontraram maior produtividade com 140 


\section{Ano 1}

- $0 y=-58,861 x^{2}+924,9 x+2250,2\left(R^{2}=0,8935\right) P \max : 7,86$

- $50 y=-84,366 x^{2}+1220,9 x+2552,1\left(R^{2}=0,9937\right) P \max : 7,24$

$\Delta 100 y=-83,251 x^{2}+1340,7 x+1835,3\left(R^{2}=0,9738\right) P \max : 8,05$

X $150 y=-66,854 x^{2}+995,77 x+3436,1\left(R^{2}=0,8045\right) P \max : 7,45$
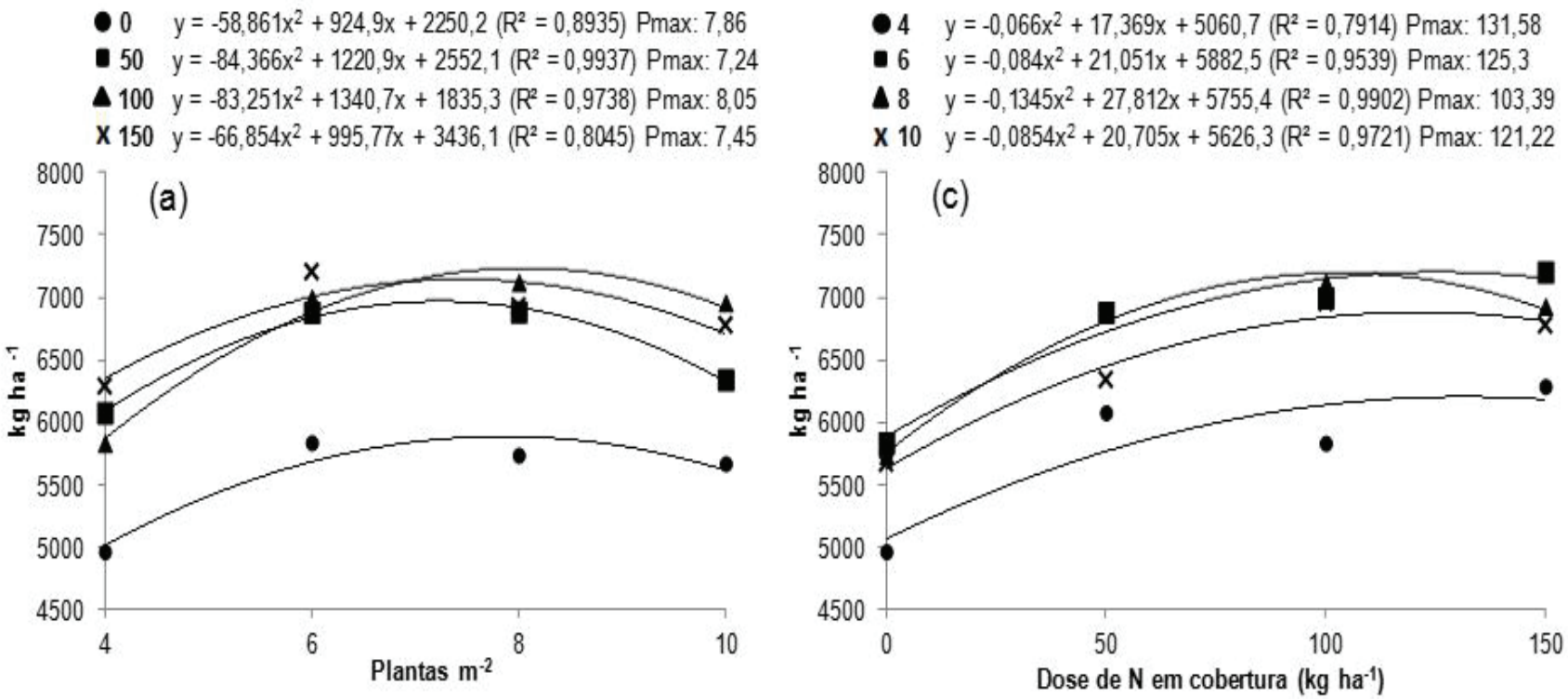

Ano 2

- $0 \quad y=5677$

- $50 y=-69,363 x^{2}+1196 x+2144,6\left(R^{2}=0,898\right) P \max : 8,62$

$\Delta 100 y=-111,23 x^{2}+1799,6 x+520,25\left(R^{2}=0,9716\right) P \max : 8,09$

X $150 y=-80,014 x^{2}+1379,2 x+1826\left(R^{2}=0,9885\right) P \max : 8,62$
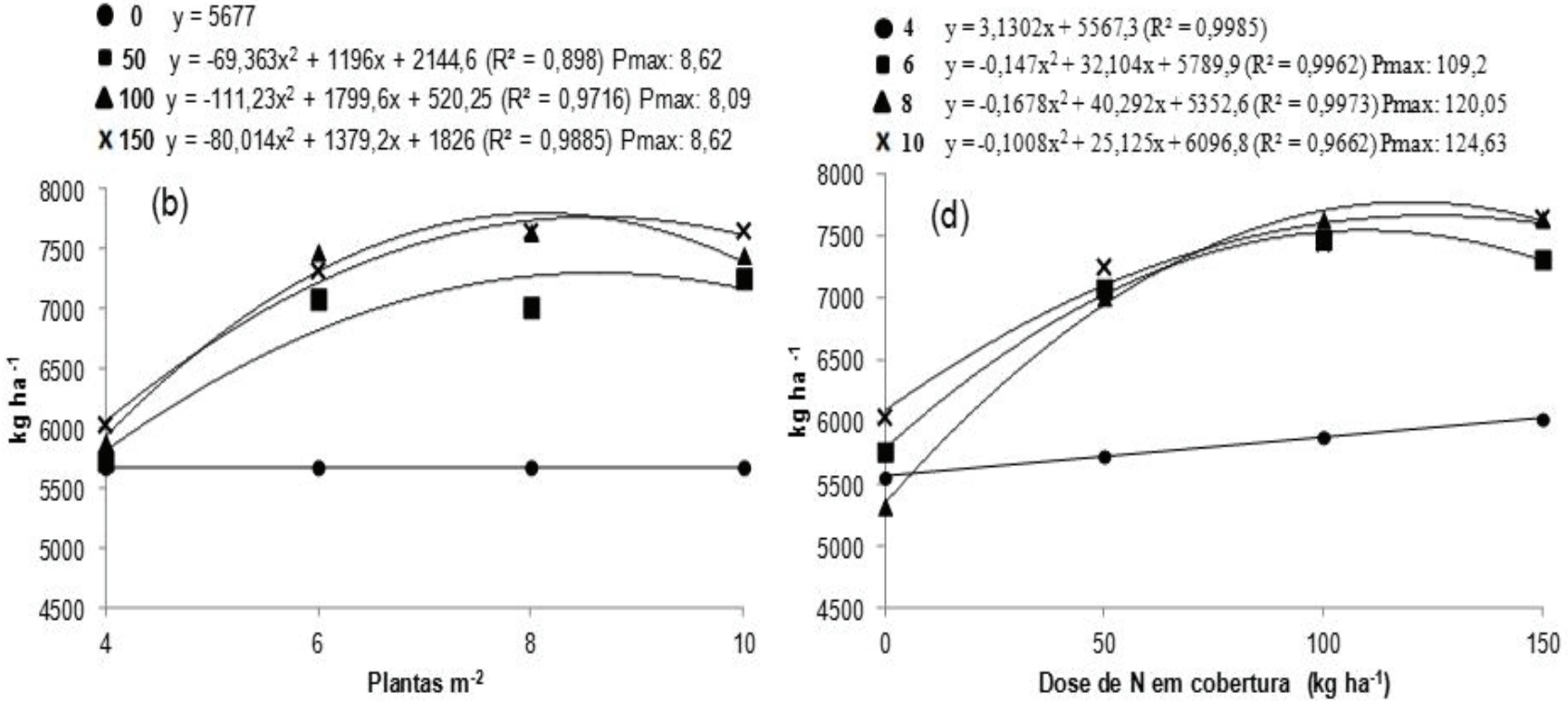

Figura 4. Produtividade de grãos $\left(\mathrm{kg} \mathrm{ha}^{-1}\right)$ em função da densidade de plantas (a e b) e de doses de nitrogênio (N) em cobertura (c e d) nos dois anos, Cambé-PR. 
Tabela 2. Produtividade de grãos entre os anos, em função de densidade de plantas e doses de nitrogênio (N) em cobertura, na cultura do milho, Cambé-PR.

\begin{tabular}{|c|c|c|c|c|c|c|c|c|}
\hline \multirow{2}{*}{$\frac{\mathrm{kg} \text { de } \mathrm{N} \mathrm{ha}^{-1}}{\text { Ano }}$} & \multicolumn{2}{|c|}{0} & \multicolumn{2}{|c|}{50} & \multicolumn{2}{|c|}{100} & \multicolumn{2}{|c|}{150} \\
\hline & 1 & 2 & 1 & 2 & 1 & 2 & 1 & 2 \\
\hline Plantas $\mathrm{m}^{-2}$ & \multicolumn{8}{|c|}{ Produtividade $\left(\mathrm{kg} \mathrm{ha}^{-1}\right)$} \\
\hline 4 & $4958 \mathrm{a}$ & $5560 \mathrm{a}$ & $6073 a$ & $5732 \mathrm{a}$ & $5828 \mathrm{a}$ & $5885 \mathrm{a}$ & $6284 a$ & $6031 \mathrm{a}$ \\
\hline 6 & $5832 \mathrm{a}$ & $5771 \mathrm{a}$ & $6878 \mathrm{a}$ & $7083 a$ & $6995 a$ & $7475 \mathrm{a}$ & $7202 a$ & $7317 \mathrm{a}$ \\
\hline 8 & $5731 \mathrm{a}$ & $5331 \mathrm{a}$ & $6882 \mathrm{a}$ & $7014 a$ & $7120 \mathrm{a}$ & $7638 \mathrm{a}$ & $6926 b$ & $7643 a$ \\
\hline 10 & $5663 a$ & $6046 a$ & $6337 b$ & $7255 \mathrm{a}$ & $6955 a$ & $7447 \mathrm{a}$ & $6774 b$ & $7649 a$ \\
\hline
\end{tabular}

Médias seguidas pela mesma letra na linha, para comparação entre anos, não diferem entre si pelo teste $F(p \leq 0,05)$.

$\mathrm{kg} \mathrm{ha}^{-1} \mathrm{~N}$ em cobertura no espaçamento de $0,45 \mathrm{~m}$, mas sem diferença quanto à densidade populacional de 60.000 ou 80.000 plantas ha $^{-1}$.

\section{Conclusões}

A produtividade de grãos é influenciada pela interação entre população de plantas e doses de $\mathrm{N}$ em cobertura, com maior rendimento na população de 80.000 plantas ha ${ }^{-1}$ aliada à aplicação de $120 \mathrm{~kg} \mathrm{ha}^{-1}$ de nitrogênio cobertura. $\mathrm{O}$ adensamento populacional aumenta a altura de plantas e de inserção da espiga e reduz o diâmetro do colmo, a massa da folha seca, o teor de nitrogênio na folha e nos grãos. $\mathrm{O}$ incremento nas doses de nitrogênio em cobertura proporciona plantas com maior altura, diâmetro de colmo, altura de inserção de espiga, massa da folha seca e teor de nitrogênio na folha e nos grãos.

\section{Referências}

ALMEIDA, M. L. D.; MEROTTO JÚNIOR, A.; SANGOI, L.; ENDER, M.; GUIDOLIN, A. F. Incremento na densidade de plantas: uma alternativa para aumentar o rendimento de grãos de milho em regiões de curta estação estival de crescimento. Ciência Rural, Santa Maria, v. 30, n. 1, p. 23-29, 2000. DOI: 10.1590/S0103-84782000000100004.
BRITO, C. H. D.; LIMA SILVEIRA, D.; BRANDÃO, A. M.; GOMES, L. S.; GOMES LOPES, M. T. Redução de área foliar em milho em região tropical no Brasil e os efeitos em caracteres agronômicos. Interciência, Caracas, v. 36, n. 4, p. 291-295, 2011.

CRUZ, J. C.; SILVA, G. H. da; PEREIRA FILHO, I. A.; NETO, M. M. G.; MAGALHÃES, P. C. Caracterização do cultivo de milho safrinha de alta produtividade em 2008 e 2009. Revista Brasileira de Milho e Sorgo, Sete Lagoas, v. 9 , n. 2 , p. $177-188,2010$.

DOI: 10.18512/1980-6477/rbms.v9n2p177-188.

FANCELLI, A. L. Ecofisiologia, fenologia e implicações básicas de manejo. In: GALVÃO, J. C. C.; BORÉM, A.; PIMENTEL, M. A. (Ed.). Milho: do plantio à colheita. Viçosa, MG: Editora UFV, 2015. p. 51-76.

FARINELLI, R.; PENARIOL， F. G.; FORNASIERI FILHO, D. Características agronômicas e produtividade de cultivares de milho em diferentes espaçamentos entre linhas e densidades populacionais. Científica, Jaboticabal, v. 40, n. 1, p. 21-27, 2012.

FERREIRA, D. F. Sisvar: a computer statistical analysis system. Ciência e Agrotecnologia, Lavras, v. 35, n. 6, p. 1039-1042, 2011.

DOI: $10.1590 / \mathrm{S} 1413-70542011000600001$.

IAPAR. Instituto Agronômico do Paraná. Monitoramento agroclimático do Paraná. Disponível em: <http:// 
www.iapar.br/arquivos/Image/monitoramento/Medias Historicas/Londrina.htm>. Acesso em: 10 jan. 2018a.

IAPAR. Instituto Agronômico do Paraná. Médias históricas em estações do IAPAR: Londrina. Disponível em: <http://www.iapar.br/arquivos/Image/monitoramento/ Medias_Historicas/Londrina.htm $>$ Acesso em: 10 jan. 2018b.

KAPPES, C.; ANDRADE, J. A. C.; ARF, O.; OLIVEIRA, A. C.; ARF, M. V.; FERREIRA, J. P. Desempenho de híbridos de milho em diferentes arranjos espaciais de plantas. Bragantia, Campinas, v. 70, n. 2, p. 334-343, 2011. DOI: $10.1590 /$ S0006-87052011000200012.

LANA, M. D. C.; RAMPIM, L.; OHLAND, T.; FÁVERO, F. Spacing, population density and nitrogen fertilization in maize grown in an Oxisoil. Ceres, Viçosa, MG, v. 61, n. 3, p. 424-433, 2014.

DOI: 10.1590/S0034-737X2014000300018.

LANA, M. D. C.; WOYTICHOSKI JÚNIOR, P. P.; BRACCINI, A. L.; SCAPIM, C. A.; ÁVILA, M. R.; ALBRECHT, L. P. Arranjo espacial e adubação nitrogenada em cobertura na cultura do milho. Acta Scientiarum Agronomy, Maringá, v. 31, n. 3, p. 433-438, 2009.

DOI: $10.4025 /$ actasciagron.v31i3.788.

MALDANER, L. J.; HORING, K.; SCHNEIDER, J. F.; FRIGO, J. P.; AZEVEDO, K. D.; GRZESIUCK, A. E. Exigência agroclimática da cultura do milho. Revista Brasileira de Energias Renováveis, v. 3, n. 1, p. 13-23, 2014.

DOI: 10.5380/rber.v3i1.36915.

MELO, F. B.; CORÁ, J. E.; CARDOSO, M. J. Fertilização nitrogenada, densidade de plantas e rendimento de milho cultivado no sistema plantio direto. Revista Ciência Agronômica, Fortaleza, v. 42, n. 1, p. 27-31, 2011.

DOI: $10.1590 /$ S1806-66902011000100004.

MODOLO, A. J.; CARNIELETTO, R.; KOLLING, E. M.; TROGEllO, E.; SGARBOSSA, M. Desempenho de híbridos de milho na Região Sudoeste do Paraná sob diferentes espaçamentos entre linhas. Revista Ciência Agronômica, Fortaleza, v. 41, n. 3, p. 435-441, 2010.

DOI: $10.1590 /$ S1806-66902010000300016.

PEREIRA, J. L. A. R.; VON PINHO, R. G.; BORGES, I. D.; PEREIRA, A.; LIMA, T. G. Cultivares, doses de fertilizantes e densidades de semeadura no cultivo de milho safrinha. Ciência e Agrotecnologia, Lavras, v. 33, n. 3, p. 676-683, 2009.

DOI: $10.1590 /$ S1413-70542009000300003.

PRADO, R. M. Nutrição de plantas. São Paulo: UNESP, 2008. v. 1.407 p.

SANGOI, L.; ALMEIDA, M. D.; LECH, V. A.; GRACIETTI, L. C.; RAMPAZZO, C. Desempenho de híbridos de milho com ciclos contrastantes em função da desfolha e da população de plantas. Scientia Agricola, Campinas, v. 58, n. 2, p. 271-276, 2001.

DOI: $10.1590 / \mathrm{S} 0103-90162001000200009$.

SANGOI, L.; SILVA, P. R. F.; ARGENTA, G.; RAMBO, L. Ecofisiologia da cultura do milho para altos rendimentos. Lages: Graphel, 2010a. 87p.

SANGOI, L.; SILVA, P. R. F. da; ARGENTA, G. Estratégias de manejo do arranjo de plantas para aumentar o rendimento de grãos de milho. SANGOI, L.; FERREIRA DA SILVA, P. R.; ARGENTA, G. Lages: Graphel, 2010b. 64 p. estava sangoi

SERPA, M. S.; SILVA, P. R. F.; SANGOI, L.; VIEIRA, V. M.; MARCHESI, D. R. Densidade de plantas em híbridos de milho semeados no final do inverno em ambientes irrigados e de sequeiro. Pesquisa Agropecuária Brasileira, Brasília, DF, v. 47, n. 4, p. 541-549, 2012.

DOI: 10.1590/S0100-204X2012000400010.

MOREIRA, A.; MOTTA, A. C. V.; COSTA, A.; MUNIZ, A. S.; CASSOL, L. C.; ZANÃO JÚNIOR, L. A.; BATISTA, M. A.; MÜLLER, M. M. L.; HAGER, N.; PAULETTI, V. (Ed.). Manual de adubação e calagem para o Estado do Paraná. Curitiba: Sociedade Brasileira de Ciência do Solo, p. 482, 2017. 
SORATTO, R. P.; PEREIRA, M.; COSTA, T. A. M.; LAMPERT, V. N. Fontes alternativas e doses de nitrogênio no milho safrinha em sucessão à soja. Revista Ciência Agronômica, Fortaleza, v. 41, n. 4, p. 511-518, 2010.

VON PINHO, R. G.; GROSS, M. R.; STEOLA, A. G.; MENDES, M. C. Adubação nitrogenada, densidade e espaçamento de híbridos de milho em sistema plantio direto na região sudeste do Tocantins. Bragantia, Campinas, v. 67, n. 3, p. 733-739, 2008.

DOI: $10.1590 / \mathrm{S} 0006-87052008000300023$.

TAIZ, L.; ZEIGER, E. Fisiologia e desenvolvimento vegetal. 6. ed. Porto Alegre: Artmed. 2017. 888 p. 